\title{
Gender-related pathways for behavior problems in the offspring of alcoholic fathers
}

\section{E.F. Furtado ${ }^{1}$, \\ M. Laucht ${ }^{2}$} and M.H. Schmidt ${ }^{2}$

\author{
${ }^{1}$ Departamento de Neurologia, Psiquiatria e Psicologia Médica, \\ Faculdade de Medicina de Ribeirão Preto, Universidade de São Paulo, \\ Ribeirão Preto, SP, Brasil \\ ${ }^{2}$ Department of Child and Adolescent Psychiatry and Psychotherapy, \\ Central Institute of Mental Health, University of Heidelberg, Mannheim, Germany
}

\section{Correspondence \\ E.F. Furtado \\ Departamento de Neurologia, \\ Psiquiatria e Psicologia Médica \\ FMRP, USP \\ Av. dos Bandeirantes, 3900 \\ 14049-900 Ribeirão Preto, SP \\ Brasil \\ Fax.: +55-16-3602-2836 \\ E-mail: efurtado@fmrp.usp.br}

This study was carried out as part of the Brazilian-German cooperation and exchange program CAPES/DAAD/PROBRAL, Project 177/04

"Drug Behavior: Risk Factors and Vulnerability Models".

The Mannheim Study of Risk Children was supported by grants from the

German Research Foundation

(Deutsche Forschungsgemeinschaft).

Publication supported by FAPESP and FAEPA.

Received March 28, 2005 Accepted January 2, 2006

\begin{abstract}
The objective of the present study was to examine gender differences in the influence of paternal alcoholism on children's social-emotional development and to determine whether paternal alcoholism is associated with a greater number of externalizing symptoms in the male offspring. From the Mannheim Study of Risk Children, an ongoing longitudinal study of a high-risk population, the developmental data of 219 children [193 (95 boys and 98 girls) of non-alcoholic fathers, non-COAs, and 26 (14 boys, 12 girls) of alcoholic fathers, COAs] were analyzed from birth to the age of 11 years. Paternal alcoholism was defined according to the ICD-10 categories of alcohol dependence and harmful use. Socio-demographic data, cognitive development, number and severity of behavior problems, and gender-related differences in the rates of externalizing and internalizing symptoms were assessed using standardized instruments (IQ tests, Child Behavior Checklist questionnaire and diagnostic interviews). The general linear model analysis revealed a significant overall effect of paternal alcoholism on the number of child psychiatric problems $(\mathrm{F}=21.872$, d.f. $=1.217, \mathrm{P}<0.001)$. Beginning at age 2 , significantly higher numbers of externalizing symptoms were observed among COAs. In female COAs, a pattern similar to that of the male COAs emerged, with the predominance of delinquent and aggressive behavior. Unlike male COAs, females showed an increase of internalizing symptoms up to age 11 years. Of these, somatic complaints revealed the strongest discriminating effect in 11-year-old females. Children of alcoholic fathers are at high risk for psychopathology. Gender-related differences seem to exist and may contribute to different phenotypes during development from early childhood to adolescence.
\end{abstract}

\section{Introduction}

Numerous clinical observations and empirical studies have identified children of alcoholics (COAs) as a group at high risk for
Key words

- Longitudinal study

- Paternal alcohol disorder

- Child development

- Psychiatric disorder

- Gender differences

- Externalizing disorders 
lems among the offspring in a cross-sectional study with children hospitalized in a German child psychiatry clinic (3). COAs were also found to be over-represented in special schools for children with learning difficulties. In a study by Schmid et al. (4), about half the children in special schools had at least one parent with alcohol-related problems. Finally, COAs have been reported to have a four-fold higher risk of alcoholism and addiction in adulthood than the general population (5).

As a risk group, COAs provide an excellent opportunity to investigate the interaction of biological and psychosocial factors. However, researchers in this area have pointed out that methodological problems leading to contradictory results can be the consequence of unsatisfactory research designs (6-8). Recently, Hill et al. (9) reported an accentuated behavioral inhibition in preschool age COAs. According to the authors, early inhibition could explain how anxiety and depression accentuate the risk for later alcohol dependence in COAs. However, when trying to repeat this study, Biederman et al. (10) found no differences between COAs and non-COAs and concluded that their results were "not consistent with the hypothesis linking behavioral inhibition to addictions". These contradictory findings could be partially due to methodological constraints. One frequent confounding variable is gender. There are important genderrelated pathways for the development of psychopathology. For instance, as opposed to girls, pre-school boys exhibit more externalizing symptoms $(11,12)$ as do older boys (13). Although conduct problems in childhood predict the same increased rates of overall psychiatric disorder in both men and women, the patterns are different: for externalizing disorders, the prediction is stronger in men, while for internalizing disorders, it is stronger in women (14). Other problems arise from different subtypes of parental alcoholism. Which parent is alcoholic makes an important difference. Alcoholic fathers seem to be more associated with an elevated risk of alcoholism in adulthood for their male offspring, an association that seems to be stronger when the father is diagnosed as antisocial $(6,15)$.

A further methodological problem derives from the age composition of the study sample. From childhood to adulthood, many age-dependent changes in developmental processes occur that have consequences for psychopathological phenotypes, e.g., internalizing symptoms in male toddlers may evolve into aggressive problems at school age. Thus, the age composition of a sample must be managed carefully. Epidemiological research on risk factors and vulnerability in COAs should take advantage of longitudinal prospective designs using communitybased and age-matched samples. Employing such an approach, the present investigation was designed to pursue the following objectives: 1) to examine the influence of paternal alcoholism on children's social-emotional development and 2) to explore gender differences and, more particularly, to determine whether paternal alcoholism is associated with a greater number of externalizing symptoms in the male offspring.

\section{Material and Methods}

\section{Study design}

This investigation was conducted within the framework of the Mannheim Study of Risk Children (MARC), which is a prospective longitudinal study following a community sample of 362 children from childbirth to adolescence, with interrelated phases of data collection $(1,2,16-18)$. The MARC was designed to permit the analysis of interactions between biological and psychosocial risk factors. Children in the sample belong to a cohort born between February 1986 and February 1988, and were recruited from two obstetric and six pediatric hospitals of the 
Rhine-Neckar region of Germany. Children were included consecutively in the study sample according to the following criteria: firstborn children of German-speaking parents, singletons with no severe physical handicaps, obvious genetic defects, or metabolic diseases. Participation rate at the time of recruitment was $64.5 \%$, with a slightly lower rate among parents from psychosocially disadvantaged backgrounds. All children were white, and the majority were of low socioeconomic status. Data were collected chronologically at the following ages for each child: 3 months and 2, 4 and half, 8, and 11 years of age.

The results presented here originated from a sample of 219 children (109 boys and 110 girls). The COA group was composed of 26 children (14 boys and 12 girls) selected according to a paternal diagnosis of alcohol disorder including the two ICD-10 main categories of alcohol dependence (F10.2) and harmful use (F10.1). The control group consisted of 193 children ( 95 boys and 98 girls), meeting the major criterion of no paternal psychiatric morbidity.

To control more rigorously for confounding factors in the family environment, only biological fathers were included. In addition, children with serious cognitive, motor and/or sensory handicaps were excluded from the sample. As shown in Table 1, the COAs' families were characterized by lower educational achievement on the part of the fathers and a lower level of family income. Fathers also had more legal problems at the time of their child's birth. No statistical differences between groups were found regarding indicators of pre- and perinatal health, such as birth weight and gestational age. More detailed information about the MARC is available in recent publications dealing with methodological aspects and results regarding the interaction between organic and psychosocial risk factors in this sample (1,2,16-18).

\section{Instruments and variables}

Paternal psychiatric problems. To assess psychiatric disorders in fathers, a twostage procedure was used. A complaint inventory, the "Beschwerdenliste B-L" by von Zerssen (19), served as a screening instrument to gather information about current paternal psychopathology. Additionally, substance abuse and delinquent behavior were examined. In a second-stage assessment, a standardized clinical interview, SCID by Spitzer, Williams and Gibbons - German version by Wittchen et al. (20), was administered by trained clinical psychologists to obtain systematic diagnoses during a prevalence period covering the past 6 months. The German SCID is based on DSM-III-R, DSMIV and ICD-10 research criteria $(20,21)$. Interviews were conducted with the mothers (and in $40 \%$ of the cases with the fathers as well) during a home visit. In case of absent

\begin{tabular}{|c|c|c|c|c|}
\hline Variable & COAs & Non-COAs & $\mathrm{F}, \mathrm{Z}, \chi^{2}$ & $\mathrm{P}$ \\
\hline Birth weight (g) & $2915 \pm 883(830-4000)$ & $2778 \pm 809(750-4200)$ & 0.371 & NS \\
\hline Gestational age (weeks) & $37.40 \pm 3.57(27-42)$ & $37.80 \pm 3.41(27-42)$ & 0.001 & NS \\
\hline Mother's age (years) & $28.46 \pm 5.33(19-40)$ & $27.91 \pm 4.41(19-41)$ & -0.362 & NS \\
\hline Father's age (years) & $32.54 \pm 5.23(24-46)$ & $30.66 \pm 5.66(20-50)$ & -2.057 & 0.039 \\
\hline No school graduation - father (\%) & $23.10 \%$ & $5.20 \%$ & 7.718 & 0.006 \\
\hline Child's gender (\% female) & $46.15 \%$ & $50.23 \%$ & 0.196 & NS \\
\hline
\end{tabular}

Data are reported as means $\pm S D$, with the range in parentheses, and as percentages. NS = differences not significant by the $t$-test (for means) and by the chi-square test for proportions. 
fathers, evaluation of paternal psychopathology relied on maternal information only. Diagnoses were made only if the information was complete and judged reliable by the interviewer. Comparisons between evaluations with and without the participation of the father showed that this procedure led to a slight underestimate of the rates of psychiatric diagnoses in fathers. As could be derived from research analyzing the concordance between direct and indirect assessment of child and adolescent psychopathology (e.g., agreement between parent and child reports), symptoms of affective and anxiety disorders were more likely to be under-reported by indirect interviews, while more externalizing disorders, such as alcohol abuse and antisocial personality disorder, were better reported by informants (22).

Child cognitive development. Cognitive development was measured by the Mental Developmental Index of the Bayley Scales of Infant Development (23) at the ages of 3 months and 2 years. The Columbia Mental Maturity Scale (24) was administered at preschool age, supplemented by the Illinois Test of Psycholinguistic Abilities (ITPA) sentence completion sub-scale $(25,26)$. The CFT1 (27) with the ITPA - sentence completion sub-scale was used at the age of 8 years. The CFT20 supplemented with the WS scale for assessment of verbal ability was administered at the age of 11 years (28).

Child psychiatric assessment. Psychiatric problems were identified through standardized interviews and questionnaires. Behavioral and emotional problems were assessed using the Mannheim Parent Interview MEI (29). The following areas of infant behavior at the age of 3 months were covered: feeding difficulties, sleeping and digestive problems. In addition, a number of temperamental characteristics such as irritability, distractibility or dysphoric mood were assessed. Measurement of temperament according to Thomas et al. (30) was obtained by behavioral ratings from the parent inter- views and from direct observations. From the age of 8 years on, a direct clinical interview with the child also became part of the child's diagnostic assessment. All diagnostic assessments were carried out in compliance with the ICD-10 research criteria.

Severity was evaluated on a seven-point scale (for dichotomous analyses, levels one to four formed the category "problems absent or clinically irrelevant", while levels five to seven identified positive cases). To determine specific psychiatric syndromes (possible from the age of 2 years on) the indicating symptoms of the diagnostic groups were organized into the categories: "externalizing behavior" and "internalizing behavior". "Externalizing behavior" at preschool age included the following symptoms: impulsiveness, hyperactivity, distractibility, oppositional behavior, temper tantrums, aggressive behavior, destructive behavior, and social disinhibition. At school age, the following symptoms were added: lying, stealing, truancy, running away from home, self-destructive behavior, suicidal behavior, psychoactive substance use, and disciplinary problems at school. The "internalizing behavior" category encompassed the following symptoms: phobias, social anxiety, generalized anxiety, depression, and symptoms related to sleep and eating behavior. The sum of psychiatric symptoms formed a continuous variable, while diagnostic classification was used as a dichotomous variable. Two diagnostic groups were formed: a) externalizing disorders (including hyperkinetic disorder (F90) and conduct disorders (F91, F92)), and b) internalizing disorders (including emotional disorders, disorders of social functioning (F93, F94) and other emotional problems (F54, F98) with specific onset in childhood).

In addition, the Child Behavior Checklist (CBCL) was administered at the ages of 8 and 11 years. The CBCL is a widely used instrument which has been translated into more than 40 languages and for which a 
considerable body of reliability and validity data has been published. The CBCL presents descriptions of 118 problem behaviors which are likely to occur in children 4 to 18 years of age. The German version of the CBCL (CBCL/4-18) $(31,32)$ was used to measure children's behavior problems as reported by their parents. The instrument's psychometric characteristics were confirmed for the German translation (32). Eight specific behavior syndrome scales were elaborated: withdrawn, somatic complaints, anxious/depressed, social problems, thought problems, attention problems, delinquent behavior, and aggressive behavior. Second-order factor analyses yielded two broad-band syndromes of externalizing and internalizing behavior problems.

\section{Statistical analysis}

To examine the effect of attribution to the case group (COAs) or to the control group (non-COAs) and of gender on cognitive and social-emotional outcome, i.e., the sum of symptoms and the level of severity of psychiatric problems across assessments, the general linear model (GLM) procedure with repeated measures was used. Univariate comparisons of continuous variables were computed by means of $t$-tests and ANOVA. To compare differences in frequencies and ratios between groups, chi-square tests and Fisher's exact tests were performed.

\section{Results}

\section{Cognitive development}

When boys and girls were examined together, children of alcoholic fathers presented lower average scores in intelligence tests across all assessments. Throughout the study period, the mean IQ of COAs was 100.53, while the control group reached an average of $102.52(\mathrm{~F}=0.770$, d.f. $=1.217, \mathrm{P}$ $=0.306)$. This observed difference with lower average among COAs did not reach statistical significance. The differences were more marked among males than among females. While the difference between male COAs and non-COAs of around four-and-a-half IQ points approached significance $(\mathrm{F}=2.571$, d.f. $=1.217, \mathrm{P}=0.112$ ), the difference observed between female COAs and non-COAs was far from being statistically significant $(\mathrm{F}=0.124$, d.f. $=1.108, \mathrm{P}=0.726)$.

\section{Psychiatric outcome}

Psychiatric problems. At each phase of evaluation the total sum of identified psychiatric problems was computed. Figure 1 shows a steady increase from 3 months to 8 years of age as the number of problems tended to grow with the age of the child. The GLM analysis revealed a significant overall effect of paternal alcoholism on the number of child psychiatric problems $(\mathrm{F}=21.872$, d.f. $=1.217, \mathrm{P}<0.001)$. While at 3 months of age, no significant difference was identified $(\mathrm{P}=0.767)$, beginning at 2 years of age the mean sum of psychiatric problems in the COA group was significantly higher than in the control group and remained so up to 11 years of age (all $\mathrm{P}<0.01$ ).

Externalizing symptoms. Since diagnostic assessments are much more reliable after 2 years of age, only the period between the ages of 2 and 11 years was considered. Using GLM analysis, significant main effects of COA group membership ( $\mathrm{F}=23.357$, d.f.

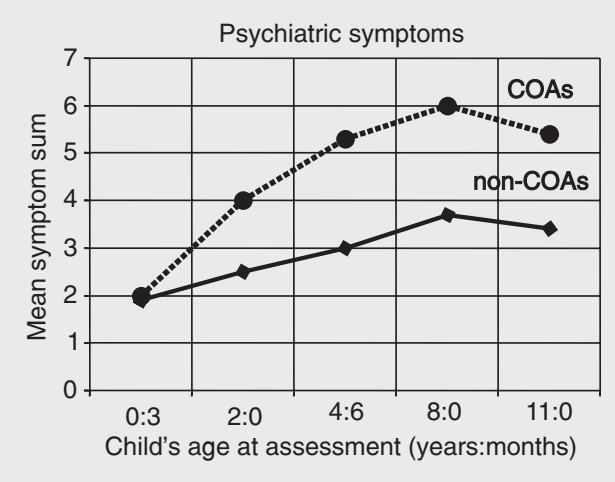

Figure 1. Longitudinal effect of paternal alcoholism on the development of child behavior problems. $\mathrm{COAs}=$ children of alcoholic fathers; non-COAs = children of non-alcoholic fathers. 
$=1.215, \mathrm{P}<0.001)$ and of gender $(\mathrm{F}=$ 12.279 , d.f. $=1.215, \mathrm{P}<0.001)$ on externalizing scores were obtained. As shown in Figure 2, both male and female COAs had significantly more externalizing symptoms when compared to the control group at all assessments. While the shape of the curves was similar, the mean number of externalizing symptoms for male and female COAs differed, with males showing more symptoms on average. However, the comparisons within the gender groups revealed that both male and female COAs were characterized

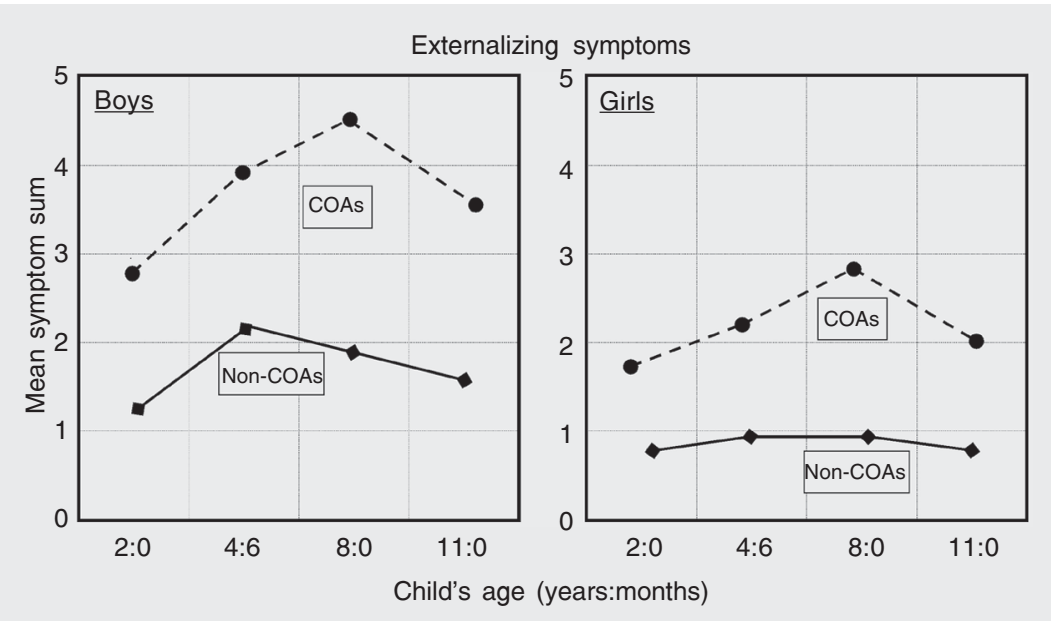

Figure 2. Longitudinal effect of paternal alcoholism on the development of externalizing symptoms in males and females. COAs = children of alcoholic fathers; non-COAs = children of non-alcoholic fathers.

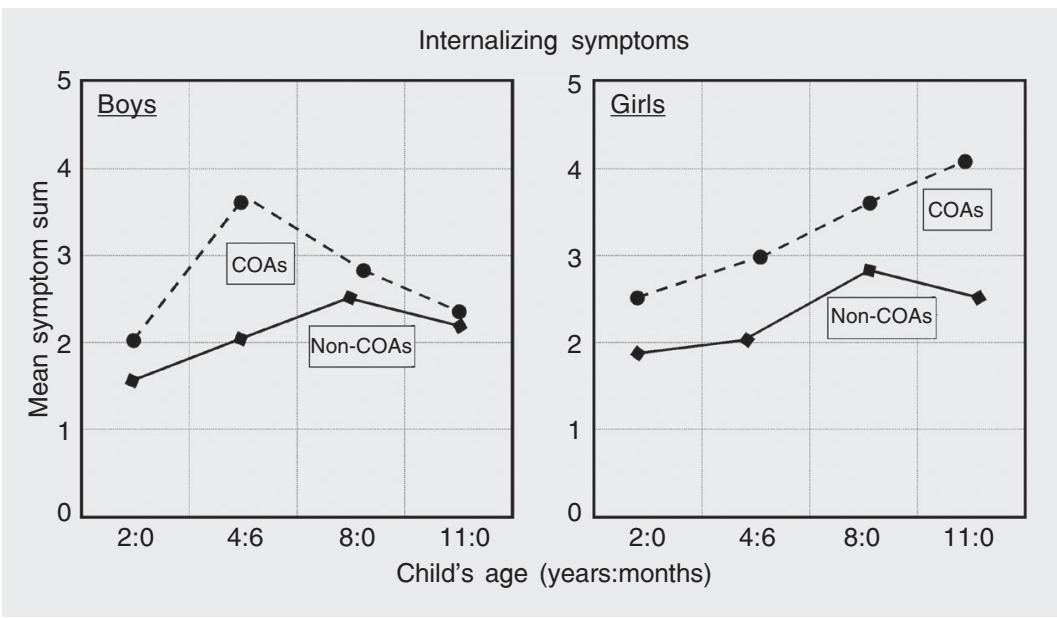

Figure 3. Longitudinal effect of paternal alcoholism on the development of internalizing symptoms in males and females. COAs = children of alcoholic fathers; non-COAs = children of non-alcoholic fathers. by scores higher than those for male and female non-COAs.

While $29.8 \%$ of the COAs were diagnosed with an externalizing disorder, the control group had only $10.8 \%$ cases diagnosed for the period from 2 to 11 years of age. The comparisons of 2-year-old COAs and non-COAs revealed no significant differences, although the rates of externalizing disorders were found to be almost twice as high, with an odds ratio of 1.9 (95\% CI = $\left.0.6-6.1 ; \chi^{2}=1.006 ; \mathrm{NS}\right)$. The odds ratios for the 4-and-a-half, 8 - and 11-year-old children were 4.4 $\left(95 \% \mathrm{CI}=1.8-10.8 ; \chi^{2}=9.497\right.$; $\mathrm{P}=0.002), 4.6\left(95 \% \mathrm{CI}=1.8-11.6 ; \chi^{2}=\right.$ $9.169 ; \mathrm{P}=0.002)$ and $3.6(95 \% \mathrm{CI}=1.3-8.9$; $\left.\chi^{2}=5.921 ; \mathrm{P}=0.013\right)$, respectively.

Internalizing symptoms. Comparison of the occurrence of internalizing disorders between groups indicated no significant differences, with frequencies remaining below $10 \%$ in both groups. However, GLM analysis yielded a significant group effect on the number of internalizing symptoms between the ages of 2 and 11 years $(\mathrm{F}=7.451$, d.f. $=$ 1.215, $\mathrm{P}<0.01$ ). As shown in Figure 3, the shape of the curves and the mean range of the sum of internalizing symptoms were quite similar in male and female non-COAs. However, a different pattern was observed in male and female COAs, showing a tendency to statistical significance (age $\mathrm{x}$ group $\mathrm{x}$ gender interaction: $\mathrm{F}=2.826$, d.f. $=1.215$, $\mathrm{P}=0.094)$. In male COAs, after an elevation of the scores from 2 to 4-and-a-half years of age, the number of symptoms fell continuously up to 11 years. The curve for the female COAs, however, showed a continuous rise beginning at 2 years of age that reached its maximum at the age of 11 years.

CBCL scales. The $T$-scores of the CBCL scales at the ages of 8 and 11 years were compared between groups in the total sample, as well as separately for males and females. Results are presented in Table 2 for 8-yearold boys and girls, in Table 3 for 11-yearolds and in Table 4 for the total sample. At 
the age of 8 years, male COAs reached scores significantly higher than those for male nonCOAs on three CBCL scales: somatic complaints, delinquent behavior and aggressive behavior. The female COAs showed a simi- lar pattern, with significantly higher scores on the delinquent behavior and aggressive behavior scales. At the age of 11 years, however, a stronger divergence between COAs and non-COAs was observed. Male

Table 2. Gender differences: Child Behavior Checklist ratings at 8 years.

\begin{tabular}{|c|c|c|c|c|c|c|}
\hline & \multicolumn{3}{|c|}{ Males } & \multicolumn{3}{|c|}{ Females } \\
\hline & $\begin{array}{c}\text { COAs } \\
(\mathrm{N}=12)\end{array}$ & $\begin{array}{c}\text { Non-COAs } \\
(\mathrm{N}=88)\end{array}$ & $F_{1,99}$ & $\begin{array}{c}\text { COAs } \\
(\mathrm{N}=10)\end{array}$ & $\begin{array}{c}\text { Non-COAs } \\
(\mathrm{N}=93)\end{array}$ & $F_{1,102}$ \\
\hline \multicolumn{7}{|l|}{ Narrow-band syndromes } \\
\hline Withdrawn & $54.8 \pm 5.9$ & $54.8 \pm 5.8$ & NS & $54.0 \pm 4.2$ & $54.3 \pm 5.4$ & NS \\
\hline Somatic complaints & $59.3 \pm 9.3$ & $54.5 \pm 6.7$ & $4.86^{*}$ & $54.6 \pm 6.7$ & $54.5 \pm 6.6$ & NS \\
\hline Anxious/depressed & $57.0 \pm 5.7$ & $55.5 \pm 6.3$ & NS & $54.5 \pm 5.1$ & $54.6 \pm 5.6$ & NS \\
\hline Social problems & $57.0 \pm 6.7$ & $53.9 \pm 6.2$ & NS & $53.8 \pm 5.0$ & $53.5 \pm 5.8$ & NS \\
\hline Thought problems & $52.3 \pm 5.6$ & $52.5 \pm 5.3$ & NS & $50.0 \pm 0.0$ & $51.3 \pm 4.0$ & NS \\
\hline Attention problems & $57.8 \pm 6.7$ & $55.1 \pm 6.7$ & NS & $57.1 \pm 5.8$ & $54.8 \pm 7.2$ & NS \\
\hline Delinquent behavior & $58.7 \pm 8.6$ & $54.3 \pm 5.4$ & $6.33^{*}$ & $58.1 \pm 7.2$ & $54.0 \pm 5.2$ & $5.05^{\star}$ \\
\hline Aggressive behavior & $60.6 \pm 8.9$ & $55.6 \pm 6.7$ & $5.39^{*}$ & $59.9 \pm 9.3$ & $54.7 \pm 5.7$ & $6.69^{*}$ \\
\hline \multicolumn{7}{|l|}{ Broad-band syndromes } \\
\hline Externalizing & $60.1 \pm 8.7$ & $53.5 \pm 8.3$ & $6.81^{*}$ & $57.7 \pm 11.7$ & $51.8 \pm 8.5$ & $4.05^{*}$ \\
\hline Internalizing & $57.2 \pm 7.0$ & $53.5 \pm 9.0$ & NS & $53.1 \pm 6.3$ & $51.9 \pm 8.7$ & NS \\
\hline Total problems & $58.9 \pm 8.4$ & $53.5 \pm 8.5$ & $4.45^{*}$ & $55.9 \pm 7.9$ & $51.9 \pm 8.4$ & NS \\
\hline
\end{tabular}

Data are reported as mean \pm SD T scores for sons and daughters of alcoholic fathers (COAs) and for controls (non-COAs). NS = not significant.

${ }^{*} \mathrm{P} \leq 0.05$ for comparisons within groups (male and female - COAs vs non-COAs; ANOVA).

Table 3. Gender differences: Child Behavior Checklist ratings at 11 years.

\begin{tabular}{|c|c|c|c|c|c|c|}
\hline & \multicolumn{3}{|c|}{ Males } & \multicolumn{3}{|c|}{ Females } \\
\hline & $\begin{array}{c}\text { COAs } \\
(\mathrm{N}=14)\end{array}$ & $\begin{array}{c}\text { Non-COAs } \\
(\mathrm{N}=94)\end{array}$ & $F_{1,107}$ & $\begin{array}{c}\text { COAs } \\
(N=12)\end{array}$ & $\begin{array}{c}\text { Non-COAs } \\
(\mathrm{N}=94)\end{array}$ & $F_{1,105}$ \\
\hline \multicolumn{7}{|l|}{ Narrow-band syndromes } \\
\hline Withdrawn & $56.8 \pm 5.8$ & $54.6 \pm 5.7$ & NS & $55.7 \pm 6.8$ & $54.3 \pm 6.0$ & NS \\
\hline Somatic complaints & $59.0 \pm 10.3$ & $55.0 \pm 5.8$ & NS & $63.5 \pm 10.9$ & $55.3 \pm 6.6$ & $12.77^{*}$ \\
\hline Anxious/depressed & $59.8 \pm 5.7$ & $54.7 \pm 6.1$ & $5.17^{*}$ & $55.6 \pm 6.9$ & $54.4 \pm 6.2$ & $3.77^{*}$ \\
\hline Social problems & $62.8 \pm 7.4$ & $55.1 \pm 7.3$ & $11.14^{*}$ & $56.4 \pm 5.4$ & $53.6 \pm 6.0$ & NS \\
\hline Thought problems & $56.8 \pm 6.8$ & $51.6 \pm 4.2$ & $5.07^{*}$ & $51.8 \pm 3.8$ & $50.9 \pm 3.3$ & NS \\
\hline Attention problems & $61.6 \pm 12.0$ & $55.2 \pm 6.4$ & $5.65^{\star}$ & $61.1 \pm 10.3$ & $53.9 \pm 6.0$ & $10.96^{*}$ \\
\hline Delinquent behavior & $59.4 \pm 10.7$ & $54.3 \pm 5.9$ & $5.48^{*}$ & $59.3 \pm 8.0$ & $52.7 \pm 4.5$ & $21.31^{*}$ \\
\hline Aggressive behavior & $60.5 \pm 12.3$ & $54.5 \pm 6.0$ & $7.38^{*}$ & $57.7 \pm 10.4$ & $53.0 \pm 4.8$ & $11.81^{*}$ \\
\hline \multicolumn{7}{|l|}{ Broad-band syndromes } \\
\hline Externalizing & $58.7 \pm 12.7$ & $51.3 \pm 9.5$ & $6.00^{*}$ & $56.5 \pm 11.2$ & $49.6 \pm 7.7$ & $11.29^{*}$ \\
\hline Internalizing & $59.8 \pm 6.8$ & $53.1 \pm 8.2$ & $5.17^{*}$ & $56.0 \pm 10.9$ & $51.6 \pm 9.2$ & $4.91^{*}$ \\
\hline Total problems & $60.3 \pm 10.7$ & $51.7 \pm 8.9$ & $7.79^{\star}$ & $57.5 \pm 10.3$ & $50.1 \pm 8.2$ & $11.09^{*}$ \\
\hline
\end{tabular}


COAs scored significantly higher on six of the eight CBCL scales, including anxious/ depressed, social problems, thought problems, attention problems, delinquent behavior, and aggressive behavior. A similar picture was found in the female COA group, which presented significantly higher scores on five CBCL scales including somatic complaints, anxious/depressed, attention problems, delinquent behavior, and aggressive behavior. Differences between male subgroups were most marked on the social problems $(\mathrm{F}=11.14$, d.f. $=1.107, \mathrm{P}=0.001)$ and aggressive behavior scales $(\mathrm{F}=7.38$, d.f. $=$ 1.107, $\mathrm{P}=0.008)$. The delinquent behavior $(\mathrm{F}=21.31$, d.f. $=1.105, \mathrm{P}<0.001)$ and somatic complaint scales $(\mathrm{F}=12.77$, d.f. $=$ $1.105, \mathrm{P}=0.001)$ were the most discriminating between female COAs and non-COAs.

\section{Discussion}

\section{Strengths and limitations}

The strengths of this study lie in the recruitment procedure of a non-clinical, high- risk community sample, and in the careful approach to the assessment and diagnosis of children and fathers, continuously from childbirth up to 11 years of age. Furthermore, with the exception of the CBCL scales (implemented at the ages of 8 and 11 years), all measures were comparable for all research waves, all children were assessed at the same age, and the sample was, in general, wellbalanced for common confounding variables, with an overload of families at risk (which did increase the likelihood of cases). The limitations of the study are mostly related to the sample size and the small subgroup by gender. Although the GLM statistical approach we have used allows for the identification of effects during a period of time and has shown robust and reliable results, we cannot be sure about the generalizability of our findings (33). However, to the best of our knowledge, there are only few prospective longitudinal studies with the characteristics of our study and several of these studies also suffer from problems of small sample sizes at the level of subgroup analysis. Other longitudinal studies with larger samples of

\begin{tabular}{|c|c|c|c|c|c|c|}
\hline & \multicolumn{3}{|c|}{8 years } & \multicolumn{3}{|c|}{11 years } \\
\hline & $\begin{array}{c}\text { COAs } \\
(\mathrm{N}=22)\end{array}$ & $\begin{array}{c}\text { Non-COAs } \\
(\mathrm{N}=181)\end{array}$ & $F_{1,202}$ & $\begin{array}{c}\text { COAs } \\
(N=26)\end{array}$ & $\begin{array}{c}\text { Non-COAs } \\
(\mathrm{N}=188)\end{array}$ & $\mathrm{F}_{1,213}$ \\
\hline \multicolumn{7}{|l|}{ Narrow-band syndromes } \\
\hline Withdrawn & $54.5 \pm 5.1$ & $54.6 \pm 5.6$ & NS & $56.3 \pm 6.1$ & $54.5 \pm 5.8$ & NS \\
\hline Somatic complaints & $57.1 \pm 8.4$ & $54.6 \pm 6.7$ & NS & $61.1 \pm 10.6$ & $55.2 \pm 6.2$ & $13.76^{*}$ \\
\hline Anxious/depressed & $55.9 \pm 5.4$ & $55.1 \pm 6.0$ & NS & $57.9 \pm 6.5$ & $54.5 \pm 6.1$ & $9.08^{*}$ \\
\hline Social problems & $55.6 \pm 6.1$ & $53.7 \pm 6.0$ & NS & $59.9 \pm 7.2$ & $54.3 \pm 6.7$ & $11.06^{*}$ \\
\hline Thought problems & $51.2 \pm 4.2$ & $52.0 \pm 4.7$ & NS & $54.5 \pm 6.1$ & $51.3 \pm 3.8$ & $7.24^{*}$ \\
\hline Attention problems & $57.5 \pm 6.2$ & $55.0 \pm 6.9$ & NS & $61.4 \pm 11.0$ & $54.5 \pm 6.2$ & $15.79^{*}$ \\
\hline Delinquent behavior & $58.5 \pm 7.8$ & $54.1 \pm 5.3$ & $11.65^{*}$ & $59.4 \pm 9.4$ & $53.5 \pm 5.3$ & $20.58^{*}$ \\
\hline Aggressive behavior & $60.3 \pm 8.9$ & $55.1 \pm 6.3$ & $12.23^{*}$ & $59.2 \pm 11.3$ & $53.7 \pm 5.5$ & $18.29^{*}$ \\
\hline \multicolumn{7}{|l|}{ Broad-band syndromes } \\
\hline Externalizing & $59.0 \pm 10.0$ & $52.6 \pm 8.4$ & $11.01^{*}$ & $57.7 \pm 11.8$ & $50.4 \pm 8.7$ & $16.35^{\star}$ \\
\hline Internalizing & $55.3 \pm 6.9$ & $52.7 \pm 8.9$ & NS & $58.1 \pm 8.9$ & $52.3 \pm 8.7$ & $10.20^{*}$ \\
\hline Total problems & $57.6 \pm 8.1$ & $52.7 \pm 8.5$ & $6.68^{*}$ & $59.0 \pm 10.4$ & $50.9 \pm 8.6$ & $18.70^{*}$ \\
\hline
\end{tabular}

Data are reported as mean \pm SD T scores for sons and daughters of alcoholic fathers (COAs) and for controls (non-COAs). NS = not significant.

${ }^{*} \mathrm{P} \leq 0.05$ for comparisons within groups (male and female - COAs vs non-COAs; ANOVA). 
positive cases of alcoholic fathers have not anticipated prospective assessments beginning at childbirth (34-36). Most previous studies have sampled children or adolescents within a broad age range and did not allow careful observations of developmental changes as has been done in the present study.

\section{Genetic-environmental approach}

Children of parents with psychiatric disorders are considered to be at high risk for the development of behavior problems. This clinical and empirical observation raised questions about possible models of causality that could describe the process of intergenerational transmission of psychopathology. Recently, more attention has been paid to the role of genetic factors in this process $(37,38)$. In addition, stress from the social and familial environment has been frequently associated with the development of psychiatric disorders. The interaction of genetic and environmental factors makes it extremely difficult to disentangle the etiological processes underlying this association. At the level of complex social behavior, identifying a single factor that would explain a unilateral causality model has been an insolvable task. Consequently, researchers in psychiatry have been more inclined to develop multifactorial models. The children of alcoholics are an excellent example of the complex interactions between genetic and socio-environmental factors. Research on COAs has benefited from well-conceptualized multifactorial theoretical models (38).

Empirical evidence supporting a genetic explanation of the higher psychiatric risk found in children of alcoholics has increased in the past decade. Some researchers have corroborated the hypothesis of a relation between candidate genes and certain phenotypic behavioral characteristics that are related to a profile of personality risk traits, as suggested by Cloninger and colleagues (39).
Recent findings indicating differences in the expression of the regulating gene of the D2dopamine receptor, which seems to be associated with the occurrence of externalizing symptoms, or with behavioral disinhibition, in children of alcoholics (40), are an encouraging contribution towards clarifying the high prevalence of externalizing symptoms and the comparatively higher risk for the development of alcohol disorder in adolescence and early adulthood.

The results presented here corroborate in a sample of German children the high risk of a deviant developmental course of COAs. Our results indicated a similar pattern of psychopathological problems in male and female COAs. In particular, to be a son or a daughter of an alcoholic father was associated with an increased risk for the development of externalizing symptoms such as aggressive and delinquent behavior.

However, not only externalizing problems were found to discriminate between COAs and non-COAs. Interestingly, the highest CBCL scores for both male and female COAs were obtained on scales from the internalizing spectrum. Among female COAs a trend was observed, particularly at the age of 11 years, suggesting a different pathway of psychopathology with an increase of internalizing symptoms.

The high psychiatric problem scores found in our study have to be interpreted in the context of the inclusion criteria for our sample, which had specifically pursued individuals and families with a high load of biological and psychosocial risk. These findings show the high risk exposure of the offspring of alcoholic fathers and the fragility of this group in comparison to other children raised in a common context.

Unfavorable psychosocial factors, more prevalent in our sample, may influence child development indirectly, while others, such as father's individual characteristics, exert a more direct influence. These latter factors, already present at the child's birth, allow us 
to presume that deviant paternal personality characteristics at the level of social functioning may be important in the process of intergenerational transmission of psychopathology. The results of our study are suggestive and encourage more investigation of both genetic and environmental factors which can potentially aggravate or reduce risk.

We conclude that children of alcoholic fathers are at high risk for psychopathology.
There are similar patterns for male and female COAs in early childhood, when COAs present significantly more externalizing symptoms. A trend occurs in the prepubertal age when female COAs show more internalizing symptoms than female non-COAs. Future studies can be improved by the inclusion of genetic analysis, searching for links and pathways for paternal alcoholism and externalizing disorders in the offspring.

\section{References}

1. Furtado EF, Laucht M \& Schmidt MH (2002). Psychische Auffälligkeiten von Kindern alkoholkranker Väter (Psychological symptoms in children of alcoholic fathers). Zeitschrift für Kinder- und Jugendpsychiatrie und Psychotherapie, 30: 241-250.

2. Furtado EF, Laucht M \& Schmidt MH (2002). Estudo longitudinal prospectivo sobre risco de adoecimento psiquiátrico na infância e alcoolismo paterno. (Longitudinal prospective study of psychiatric risk in childhood and paternal alcoholism). Revista de Psiquiatria Clinica, 29: 74-83.

3. Steinhausen HC, Gobel D \& Nestler V (1984). Psychopathology in the offspring of alcoholic parents. Journal of the American Academy of Child and Adolescent Psychiatry, 4: 465-471.

4. Schmid W, Bachler A, Frey D et al. (1983). Genetic, medical and psychosocial factors in learning disorders in a cohort of 11-year-old children (Winterthur study). Acta Paedopsychiatrica, 49: 9-45.

5. Goodwin DW (1983). The genetics of alcoholism. Hospital and Community Psychiatry, 34: 1031-1034.

6. Chassin L, Jacob T, Johnson JL et al. (1997). Historical perspectives - a critical analysis of COA research. Alcohol Health and Research World, 3: 258-264.

7. Reich W (1997). Prospective studies of children of alcoholic parents. Alcohol Health and Research World, 3: 255-257.

8. Windle M (1997). Concepts and issues in COA research. Alcohol Health and Research World, 3: 185-191.

9. Hill SY, Lowers L, Locke $J$ et al. (1999). Behavioral inhibition in children from families at high risk for developing alcoholism. Journal of the American Academy of Child and Adolescent Psychiatry, 4: 410-417.

10. Biederman J, Hirshfeld-Becker DR, Rosenbaum JF et al. (2001). Lack of association between parental alcohol or drug addiction and behavioral inhibition in children. American Journal of Psychiatry, 10: 1731-1733.

11. Gadow KD, Sprafkin J \& Nolan EE (2002). DSM-IV symptoms in community and clinic pre-school children. Journal of the American Academy of Child and Adolescent Psychiatry, 12: 1383-1392.

12. Lavigne JV, Gibbons RD, Christoffel KK et al. (1996). Prevalence rates and correlates of psychiatric disorders among pre-school children. Journal of the American Academy of Child and Adolescent Psychiatry, 2: 204-214.

13. Lahey BB, Schwab-Stone M, Goodman SH et al. (2000). Age and gender differences in oppositional behavior and conduct problems: a cross-sectional household study of middle childhood and adolescence. Journal of Abnormal Psychology, 3: 488-503.
14. Offord DR \& Bennett KJ (1994). Conduct disorder: long-term outcomes and intervention effectiveness. Journal of the American Academy of Child and Adolescent Psychiatry, 8: 1069-1078.

15. Hussong AM, Curran PJ \& Chassin L (1998). Pathways of risk for accelerated heavy alcohol use among adolescent children of alcoholic parents. Journal of Abnormal Child Psychology, 6: 453-466.

16. Laucht M, Esser G \& Schmidt MH (1997). Developmental outcome of infants born with biological and psychosocial risks. Journal of Child Psychology and Psychiatry and Allied Disciplines, 7: 843-853.

17. Laucht M, Esser G \& Schmidt MH (2000). Externalizing and internalizing disorders in childhood: Studies on developmental psychopathology. Zeitschrift für Klinische Psychologie und Psychotherapie, 4: 284-292.

18. Laucht M, Esser G \& Schmidt MH (2000). Longitudinal research on the developmental epidemiology of mental disorders: aims, concepts, and major results of the Mannheim Study of at Risk Children. Zeitschrift für Klinische Psychologie und Psychotherapie, 4: 246262.

19. Zerssen D (1976). Die Beschwerdenliste. Beltz, Weinheim, Germany.

20. Wittchen HU, Zaudig M \& Fydrich T (1997). Strukturiertes Klinisches Interview für DSM-IV Achse I und II - SKID. Hogrefe, Göttingen, Germany.

21. Saß H, Wittchen HU, Zaudig M et al. (1998). Diagnostische Kriterien des Diagnostischen und Statistischen Manuals Psychischer Störungen DSM-IV. Hogrefe, Göttingen, Germany.

22. Edelbrock C, Costello AJ, Dulcan MK et al. (1986). Parent-child agreement on child psychiatric symptoms assessed via structured interview. Journal of Child Psychology and Psychiatry and Allied Disciplines, 2: 181-190.

23. Bayley N (1969). Bayley Scales of Infant Development. Psychological Corporation, New York.

24. Burgemeister B, Blum L \& Lorg J (1972). Columbia Mental Maturity Scale. Harcourt Brace Jovanovich, New York.

25. Kirk SA, McCarthy J \& Kirk WD (1968). Illinois Test of Psycholinguistic Abilities. University of Illinois Press, Urbana, IL, USA.

26. Angermaier M (1974). Psycholinguistischer Entwicklungstest. Beltz, Weinheim, Germany.

27. Weiß RH \& Osterland J (1977). Grundintelligenztest CFT 1. Westermann, Braunschweig, Germany.

28. Weiß RH (1997). Grundintelligenztest Skala 2 (CFT 20) mit Wortschatztest (WS) und Zahlenfolgentest (ZF) (CFT 20). Hogrefe, Göttingen, Germany. 
29. Esser G, Blanz B, Geisel B et al. (1989). Mannheimer Elterninterview - Strukturiertes Interview zur Erfassung von kinderpsychiatrischen Auffälligkeiten. Beltz, Weinheim, Germany.

30. Thomas A, Chess A \& Birch HG (1968). Temperament and Behavior Disorders in Children. University Press, New York.

31. Achenbach TM (1991). Manual for the Child Behavior Checklist/418 and 1991 Profile. Department of Psychiatry, University of Vermont, Burlington, VT, USA.

32. Dopfner M, Schmeck K, Berner W et al. (1994). Reliability and factorial validity of the Child Behavior Checklist - an analysis of a clinical and field sample. Zeitschrift für Kinder und Jugendpsychiatrie, 3: 189-205.

33. Diggle PJ, Liang KY \& Zeger SL (1996). Analysis of Longitudinal Data. Clarendon Press, Oxford, UK.

34. Schuckit MA, Smith TL, Radziminski S et al. (2000). Behavioral symptoms and psychiatric diagnoses among 162 children in nonalcoholic or alcoholic families. American Journal of Psychiatry, 157: 1881-1883.
35. Schuckit MA, Smith TL, Barnow S et al. (2003). Correlates of externalizing symptoms in children from families of alcoholics and controls. Alcohol and Alcoholism, 38: 559-567.

36. Barnow S, Schuckit M, Smith TL et al. (2002). The relationship between the family density of alcoholism and externalizing symptoms among 146 children. Alcohol and Alcoholism, 37: 383-387.

37. Merikangas KR \& Avenevoli S (2000). Implications of genetic epidemiology for the prevention of substance use disorders. Addictive Behaviors, 6: 807-820.

38. Tarter RE \& Vanyukov M (1994). Alcoholism: a developmental disorder. Journal of Consulting and Clinical Psychology, 6: 1096-1107.

39. Cloninger CR, Sigvardsson S \& Bohman M (1988). Childhood personality predicts alcohol abuse in young adults. Alcohol Clinical and Experimental Research, 4: 494-505.

40. Ozkaragoz T \& Noble EP (2000). Extraversion. Interaction between D2 dopamine receptor polymorphisms and parental alcoholism. A/cohol, 3: 139-146. 